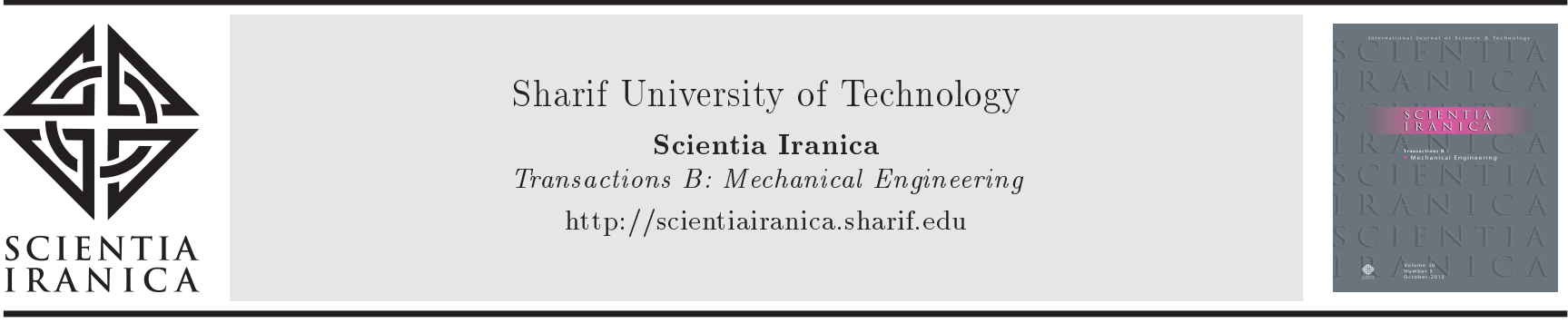

\title{
Effect of several heated interior bodies on turbulent natural convection in enclosures
}

\author{
A. Nouri-Borujerdi* and F. Sepahi \\ School of Mechanical Engineering, Sharif University of Technology, Azadi Avenue, Tehran, Iran.
}

Received 27 December 2016; received in revised form 3 December 2017; accepted 18 June 2018

\section{KEYWORDS \\ Natural convection; \\ Enclosure; \\ Interior bodies; \\ Turbulent flow; \\ Numerical method.}

\begin{abstract}
In this study, turbulent natural convection in a square enclosure including one or four hot and cold bodies is numerically investigated in the range of Rayleigh numbers of $10^{10}<\mathrm{Ra}<10^{12}$. The shape of the internal bodies is square or rectangular with the same surface areas and different aspect ratios. In all cases, the horizontal walls of the enclosure are adiabatic, and the vertical ones are isothermal. It is desired to investigate the influence of different shapes and arrangements of internal bodies on the heat transfer rate inside the enclosure with wide-ranging applications such as ventilation of buildings, electronic cooling, and industrial cold box packages. Governing equations, including Reynolds-averagedNavier-Stokes equations, have been solved numerically with finite volume method and $k-\varepsilon$ turbulence model in a staggered grid. The boundary condition for the turbulence model is based on the standard wall function approach. The strongly implicit method is employed to solve the discretized systems of algebraic equations with a remarkable rate of convergence. The effects of several parameters, such as the distance between the bodies, aspect ratio, and Rayleigh number, on the heat transfer rate have been investigated. The most noticeable change in the heat transfer rate at high values of Rayleigh numbers is associated with alteration in the distance between square bodies. Moreover, the horizontal installation of rectangular bodies with $h / w=1 / 3$ is accompanied by a maximum reduction of heat transfer at low Rayleigh numbers. The present results have been compared with previous experimental and numerical works regarding enclosures with or without internal bodies. Then, reasonable agreement is observed.
\end{abstract}

(C) 2019 Sharif University of Technology. All rights reserved.

\section{Introduction}

Natural convection is one of the most prevalent phenomena in our daily life and industry with many engineering applications such as ventilation of buildings with radiators, double-glazed windows, solar collectors, and cooling of electronic equipment. Accordingly, it has been widely considered in many experimental and

\footnotetext{
* Corresponding author. Tel.: +982166165547;

Fax: +982166000021

E-mail address: anouri@sharif.edu (A. Nouri-Borujerdi)
}

doi: $10.24200 /$ sci. 2018.20588 numerical research studies over the past decades, most of which involved natural convection within enclosures that are abundantly demanded by industrial instruments.

Several experimental works involving natural convection inside enclosures have been done in the past decades that provide useful data regarding thermal and flow fields and turbulence quantities for validation of numerical simulations. Most of these works have dealt with tall cavities at high Rayleigh numbers such as enclosures with aspect ratios of 5 in Bowles and Cheezewright [1], 3.84 in Saury et al. [2], and 28.6 in Dafa'Alla and Betts [3] and Betts and Bokhari [4] investigations. A cubic water-filled cavity at high 
Rayleigh numbers was first tested by Kirkpatrick and Bohn [5]. Later, low turbulent natural convection in an air-filled square enclosure at $\mathrm{Ra}=1.5 \times 10^{9}$ was experimented in works of Tian and Karayiannis [6,7]. Further studies for the same cavity regarding mean and fluctuation quantities were performed by Ampofo and Karayiannis [8]. Salat et al. [9] performed an experiment on an analogous cavity with the same Rayleigh number to validate their numerical results. Laminar natural convection in a set of air-filled cavities with Rayleigh numbers up to $\mathrm{Ra}=10^{6}$ was first numerically studied by De Vahl Davis [10] and, then, improved by Hortmann et al. [11] by using much finer grids. Le Quere [12] utilized different accurate methods in cavities with Rayleigh numbers up to $\mathrm{Ra}=10^{8}$. However, at large enclosures which are of interest to the present study, the Rayleigh number exceeds the critical value approximately equal to $10^{9}$ that makes the flow regime time dependent and turbulent. Hence, utilizing a proper model for turbulence is of great importance and has extensively been investigated in previous researches. Phillips [13] used $k-\varepsilon$ turbulence model for the simulation of an air-filled cavity up to $\mathrm{Ra}=10^{14}$ with wall functions established by Launder and Spalding [14]. In tall cavities simulated by Ince and Launder [15] with aspect ratios of $30: 1$ and $5: 1$, it is found that the version of Jones and Launder's [16] low-Reynolds-number $k-\varepsilon$ model produces accurate results in satisfactory agreement with the reported experimental data. Henkes et al. [17] conducted a study on turbulent natural convection inside a cavity with different versions of low-Reynolds-number $k-\varepsilon$ model and also standard $k-\varepsilon$ model with wall functions defined for $k$ and $\varepsilon$ variables. The Nusselt numbers obtained by low-Reynolds-number $k-\varepsilon$ models are found to be in better agreement with experimental data; however, the standard $k-\varepsilon$ model predicts higher corresponding Nusselt numbers. Barakos and Mitsoulis [18] studied laminar and turbulent natural convection numerically in an air-filled cavity at various Rayleigh numbers up to $\mathrm{Ra}=10^{10}$. The results indicate that even though standard $k-\varepsilon$ model with logarithmic wall functions employed for velocity and temperature overpredicts averaged Nusselt number of the hot wall, it performs reasonably when wall functions are defined only for $k$ and $\varepsilon$ at first computational grid points after the walls. In five different $k-\varepsilon$ models examined by Chen [19], low-Reynolds-number model shows better performance in the cavity than the standard and RNG $k-\varepsilon$ models; however, the standard model displays acceptable precision close to experimental data by using a much coarser grid and lower computational cost. Other studies on turbulent natural convection inside enclosures with various methods and wall functions were presented in works of Trias et al. [20,21], Hsieh and Lien [22], Hanjalić and Vasić [23], and Dol et al. [24], and new wall functions applicable to turbulent natural convection were developed by Craft et al. [25]. In addition, a comprehensive review was performed by Baïri et al. [26] that considered a broad range of experimental, analytical, and numerical studies over natural convection in enclosures with various geometries, thermal boundary conditions, and working fluids.

Many of the recent researchers have taken the importance of this problem into account and conducted a numerical simulation of natural convection inside these enclosures with different geometries and boundary conditions of interior obstacles. Ho et al. [27,28] numerically and experimentally studied laminar natural convection of two heated cylinders confined in a circular insulated enclosure or subjected to external convection at $10^{4}<\mathrm{Ra}<10^{7}$. Ha et al. [29,30] considered the effects of Prandtl number on transient natural convection inside a cavity with a central square body under different thermal conditions at $10^{3} \leq \mathrm{Ra} \leq 10^{6}$. Oztop et al. [31,32] investigated laminar natural convection at $10^{3} \leq \mathrm{Ra} \leq 10^{6}$ in square cavities including a heated plate built-in horizontally and vertically with different aspect ratios or an isothermal partition attached to the bottom wall. Numerical studies regarding square enclosures containing two mutually orthogonal heated baffles in different boundary conditions were carried out in Kandaswamy et al. [33] and Hakeem et al. [34] to evaluate the effects of baffles' length and position on heat transfer rate. Later, many researchers studied the natural convection mechanism of heat transfer in square enclosures including one or two inner heated cylinders positioned at different vertical and horizontal locations in the range of Rayleigh numbers of $10^{3} \leq$ $\mathrm{Ra} \leq 10^{6}$ [35-37] and Park et al. [38]. Garoosi et al. [39] and Garoosi and Hoseininejad [40] investigated the effects of position, size, aspect ratio, and orientation on natural and mixed convection heat transfer between heated circular or square cylinders in an enclosure filled with nanofluids at $10^{4} \leq \mathrm{Ra} \leq 10^{7}$.

In the above-mentioned studies, various numerical methods were involved to model the turbulence within empty enclosures in different boundary conditions and values of Rayleigh number. Then, a number of important works about natural convection inside enclosures, including some kind of obstacles, were reviewed, all of which were conducted at low values of Rayleigh number. Hence, the need for some numerical or experimental data about turbulent natural convection inside large enclosures with heated internal bodies at high Rayleigh numbers is impressive here, and it has not ever been investigated in the literature to the best of authors' knowledge. Accordingly, the main purpose of this work is to study turbulent buoyancy-driven convection inside large enclosures containing several hot and cold bodies with applications in chemical complex industry where cold box packages with brazed 
heat exchangers are used. Natural convection takes place at high Rayleigh numbers inside large enclosures of these packages, and the flow field is partly or fully turbulent depending on how large the Rayleigh number is. Therefore, it is desired to find the best position and orientation of heated and cooled bodies as representatives for interior heat exchangers for having access to an optimum heat transfer rate between them.

\section{Physical problem}

Figure (1(a) and (b)) shows the schematic of two square enclosures, one of which includes a single square hot body and the other consists of two hot and two cold bodies with their corresponding boundary conditions. The vertical and horizontal walls of the enclosure are isothermal and adiabatic, respectively. The hot bodies are colored by red which stands for $\theta=1$, and the cold bodies are colored by blue showing the dimensionless temperature of $\theta=0$. The temperature of the isothermal walls of the enclosure is $\theta=0$ regarding the case with one internal body and $\theta=0$ for the enclosure with four bodies inside. The default height and width of each interior body are assumed $w / H=h / H=0.25$, respectively. Moreover, when the effect of aspect ratio is due to be investigated, the height and width of the body are changed to 0.375 and 0.125 (or vice versa) for aspect ratios of $h / w=3$ and $1 / 3$. The surface areas of bodies are always kept constant and equal to 1 . It is assumed that we deal with the viscous flow in the enclosure filled with air $(\operatorname{Pr}=0.71)$ and with constant physical properties except for density in gravitational terms, varying linearly with the temperature determined by Boussinesqe approximation.

\section{Mathematical formulation of the governing equations}

Reynolds-Averaged-Navier-Stokes equations are adopted here to solve turbulent natural convection in an enclosure. In order to model the turbulence, lowReynolds-number $k-\varepsilon$ models have been overlooked because of two challenges including their non-unique solution depending on the initial condition and also the need for an extremely dense grid near the walls, according to Henkes et al. [17]. The second deficiency will appear more challenging when enclosures containing internal bodies are to be studied, and the need for an adequately concentrated grid increases the cost of computation dramatically. In addition, as was mentioned earlier, the standard version of $k-\varepsilon$ model with logarithmic wall functions defined on velocity and temperature has an overestimation of heat transfer in the enclosure, according to Barakos and Mitsoulis [18] study. Therefore, compared to LRN models, the standard $k-\varepsilon$ model with only the wall functions on $k$ and $\varepsilon$ at first computational grid points after the wall is used in order to lower the computation cost and predict heat transfer inside the enclosure better.

The general form of non-dimensional conservative equations of continuity, momentum, and energy, as well as transport equations of turbulent kinetic energy and dissipation rate for two-dimensional unsteady incompressible flow in the enclosure, is presented as in Eq. (1) with parameters defined in Table 1.

$$
\frac{\partial \rho \phi}{\partial t}+\frac{\partial \rho U_{j} \phi}{\partial x_{i}}=N \frac{\partial}{\partial x_{i}}\left[\Gamma \frac{\partial \phi}{\partial x_{i}}\right]+S .
$$

When the above general equation is used as a momentum equation, $\lambda_{i}=1$ if $g_{i} \neq 0$, or $\lambda_{i}=0$ if $g_{i}=0$ as defined in the table for term $S$. The other parameters of the standard $k-\varepsilon$ turbulence model in the table are presented as follows according to the proposal of Henkes et al. [17]:

$$
c_{\mu}=0.09, \quad c_{1 \varepsilon}=1.44,
$$

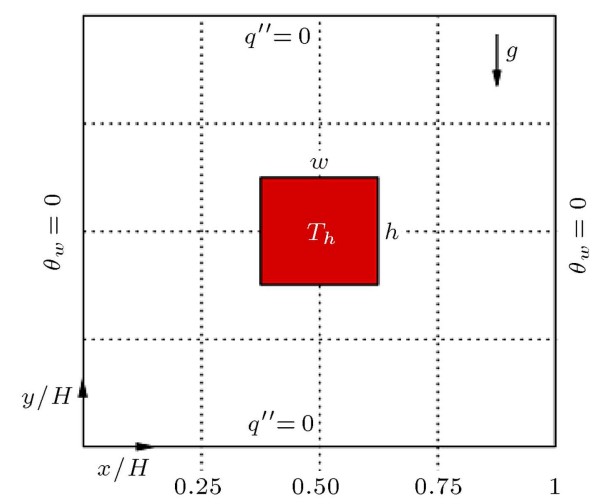

(a)

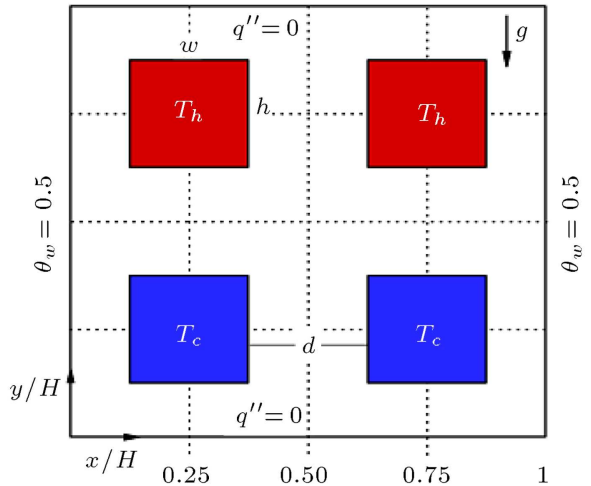

(b)

Figure 1. Schematic of enclosures with boundary conditions including: (a) A single hot body and (b) two hot and two cold bodies. 
Table 1. Definition of corresponding dimensionless parameters in Eq. (1).

\begin{tabular}{lllrl}
\hline \multicolumn{1}{c}{ Equation } & $\phi$ & $\Gamma$ & $N$ & \\
\hline Continuity & 1 & 0 & 0 & 0 \\
Momentum & $U_{i}$ & $\nu+\nu_{t}$ & $\sqrt{\mathrm{Pr} / \mathrm{Ra}}$ & $-\left(\partial P / \partial x_{i}\right) / \rho-\lambda_{i}\left(\theta-\theta_{c}\right)$ \\
Energy & $\theta$ & $\nu / \operatorname{Pr}+\nu_{t} / \sigma_{t}$ & $1 / \sqrt{\mathrm{Pr} \mathrm{Ra}}$ & 0 \\
Turbulence & $K$ & $\nu+\nu_{t} / \sigma_{k}$ & $\sqrt{\mathrm{Pr} / \mathrm{Ra}}$ & $P_{k}+G_{k}-\varepsilon$ \\
Turbulence & $\varepsilon$ & $\nu+\nu_{t} / \sigma_{\varepsilon}$ & $\sqrt{\mathrm{Pr} / \mathrm{Ra}}$ & {$\left[c_{1 \varepsilon}\left(P_{k}+c_{3 \varepsilon} G_{k}\right)-c_{2 \varepsilon} \varepsilon\right] \frac{\varepsilon}{k}$} \\
\hline
\end{tabular}

$$
\begin{aligned}
& c_{2 \varepsilon}=1.92, \quad c_{3 \varepsilon}=\tanh |u / v|, \\
& \sigma_{t}=1, \quad \sigma_{k}=1, \quad \sigma_{\varepsilon}=1.3, \\
& P_{k}=\nu_{t} \sqrt{\operatorname{Pr} / \operatorname{Ra}}\left[2\left(\frac{\partial U}{\partial X}\right)^{2}+\left(\frac{\partial U}{\partial Y}+\frac{\partial V}{\partial X}\right)^{2}\right. \\
& \left.\quad+2\left(\frac{\partial V}{\partial Y}\right)^{2}\right], \\
& G_{k}=-\frac{\nu_{t} g \beta}{\sigma_{t} \sqrt{\operatorname{Pr} \operatorname{Ra}}} \frac{\partial \theta}{\partial Y}, \quad \nu_{t}=C_{\mu} \frac{k^{2}}{\varepsilon} \sqrt{\mathrm{Ra} / \operatorname{Pr} .}
\end{aligned}
$$

The non-dimensional variables in Table 1 are defined as follows:

$$
\begin{aligned}
& (X, Y)=\frac{(x, y)}{H}, \quad(U, V)=\frac{(u, v)}{\sqrt{g \beta\left(T_{h}-T_{c}\right) H}}, \\
& \theta=\frac{T-T_{c}}{T_{h}-T_{c}}, \quad P=\frac{p}{\rho g \beta\left(T_{h}-T_{c}\right) H}, \quad \rho=\frac{\rho^{*}}{\rho_{\text {ref }}}, \\
& \varepsilon=\frac{\varepsilon^{*}}{\left[g \beta\left(T_{h}-T_{c}\right) H\right]^{3 / 2} / H}, \quad K=\frac{k}{g \beta\left(T_{h}-T_{c}\right) H}, \\
& \nu_{t}=\frac{\nu^{*}}{\nu_{\text {ref }}}, \quad t=\frac{t^{*}}{H / \sqrt{g \beta\left(T_{h}-T_{c}\right) H}} .
\end{aligned}
$$

Superscript $*$ denotes dimensional variables. The density and kinetic viscosity of laminar flow are considered as reference values of density and viscosity, respectively. The values of $k=u_{\tau}^{2} / \sqrt{c_{\mu}}$ and $\varepsilon=u_{\tau}^{3} / 0.41 Y$ are obtained in which $u_{\tau}=\sqrt{\nu \partial u / \partial y_{n}}$ is considered at the first computational grid points next to the wall.

The dimensionless initial and boundary conditions of the flow field $(\phi=U, V$ or $\theta$ ) inside the enclosure for all cases are as follows:

$$
\begin{aligned}
& \phi(X, Y, 0)=0 \\
& \phi(X, 0, t)=\phi(X, 1, t)=\phi(0, Y, t)=\phi(1, Y, t)=0 \\
& \phi\left(X_{b}, Y_{b}, t\right)=0 .
\end{aligned}
$$

Subscript $b$ denotes the body in the enclosure.
The dimensionless initial and boundary conditions of the temperature field $(\phi=\theta)$ inside the enclosure for all cases are as follows:

$\phi(X, Y, 0)=0.5$

$\frac{\partial \phi(X, 0, t)}{\partial Y}=\frac{\partial \phi(X, 1, t)}{\partial Y}=0$

$\phi(0, Y, t)=\phi(1, Y, t)$

$$
=\left\{\begin{array}{l}
0, \quad \text { with one interior body } \\
0.5, \text { with more than one interior body }
\end{array}\right.
$$

Subscripts $h$ and $c$ denote the hot and cold surfaces.

The local and averaged Nusselt numbers of the enclosure vertical wall as well as the averaged Nusselt number between the air and the surfaces of the internal bodies are defined respectively in the following:

$$
\begin{aligned}
\mathrm{Nu}_{\mathrm{w}}= & -\left.\frac{H}{\left(\mathrm{~T}_{\mathrm{h}}-\mathrm{T}_{\mathrm{c}}\right)} \frac{\partial \mathrm{T}}{\partial \mathrm{n}}\right|_{\mathrm{w}}=-\left.\frac{\partial \theta}{\partial \mathrm{n}}\right|_{\mathrm{w}}, \\
\overline{\mathrm{Nu}}_{w}= & \frac{1}{H} \int_{0}^{H} \mathrm{Nu}_{w} d y=\int_{0}^{1} \mathrm{Nu}_{w} d Y \\
\overline{\mathrm{Nu}}_{b}= & \int_{X_{c}+w / 2}^{X_{c}+w / 2}\left(\mathrm{Nu}_{\text {left }}+\mathrm{Nu}_{\text {right }}\right) d X \\
& +\int_{Y_{c}-h / 2}^{Y_{c}+h / 2}\left(\mathrm{Nu}_{\text {top }}+\mathrm{Nu}_{\text {bottom }}\right) d Y .
\end{aligned}
$$

\section{Numerical procedure}

In the subsequent sections, the computational algorithm for solving governing equations is presented and validated by previous studies, and the gridindependence will be checked subsequently.

\subsection{Computational algorithm}

To solve the set of the above non-dimensional governing partial differential equations numerically, they are discretized by the finite difference method based on finite volume approach in a staggered grid. Then, the 
SIMPLE algorithm suggested by Patankar and Spalding [41] is employed for velocity-pressure coupling. To improve the accuracy of all discretized fluxes near the wall, a finely spaced grid in $X$ - and $Y$-directions should be used, because the flow variables, such as velocity and temperature, vary rapidly near the wall surface. However, far away from the surface, the grid can be coarser. Accordingly, a multi-domain method is utilized to generate a structured mesh at the entire domain of the solution. In order to use the staggered grid, the central $U$ and $V$ velocity components have been moved to the western and southern sides of the main control volume, respectively. The other scalar variables are considered at the center of the main control volume. The hybrid and central differencing schemes are used to discretize the convective and diffusion terms of the equations, respectively. The hybrid scheme is based on the combination of central and upwind differencing schemes. The central differencing scheme, which is accurate for second order, is employed for small Peclet numbers $(\mathrm{Pe}=\mathrm{u} \Delta \mathrm{x} / \alpha<2)$; the second upwind scheme, which is accurate for second order, yet accounts for transportiveness, is employed for large Peclet numbers $(\mathrm{Pe} \geq 2)$. Time derivatives are discretized implicitly, and the spatial derivatives are computed at a new time level so that the final discretization leads to the formation of systems of linear algebraic equations that should be solved simultaneously. Two different methods have been adopted to solve the linear system of equations: line-by-line iterative and strongly implicit methods. The former method employed the tridiagonal matrix algorithm (TDMA) with alternating sweeps from left to right and bottom to top of the domain for updating variables in the solution of discretized equations. The latter one suggested by Stone [42] enabled us to reach the convergent solution at high Rayleigh numbers quickly.

For the enclosure containing interior bodies, the iterations start at $\mathrm{Ra}=10^{10}$ with TDMA method. The under-relaxation factors are set to 0.2 for turbulent kinetic energy and dissipation rate and 0.1 for the other equations. The other under-relaxation factors required to be changed are initially set to 0.3 for continuity and momentum and 0.7 for energy equations. After a number of iterations, when the residuals decrease and their oscillations stop, the solution method for the systems of the linear algebraic equations is replaced by the strongly implicit method. Subsequently, the momentum and energy under-relaxation factors are gradually reduced to 0.1 . Although this procedure brings about maximum reduction in residuals, it is not as enough as required to meet the convergence criteria defined when the residuals drop less than $10^{-3}$ for all equations except for energy, whereas the residual of the energy equation is less than $10^{-6}$. In this stage, the solution is switched over to the unsteady

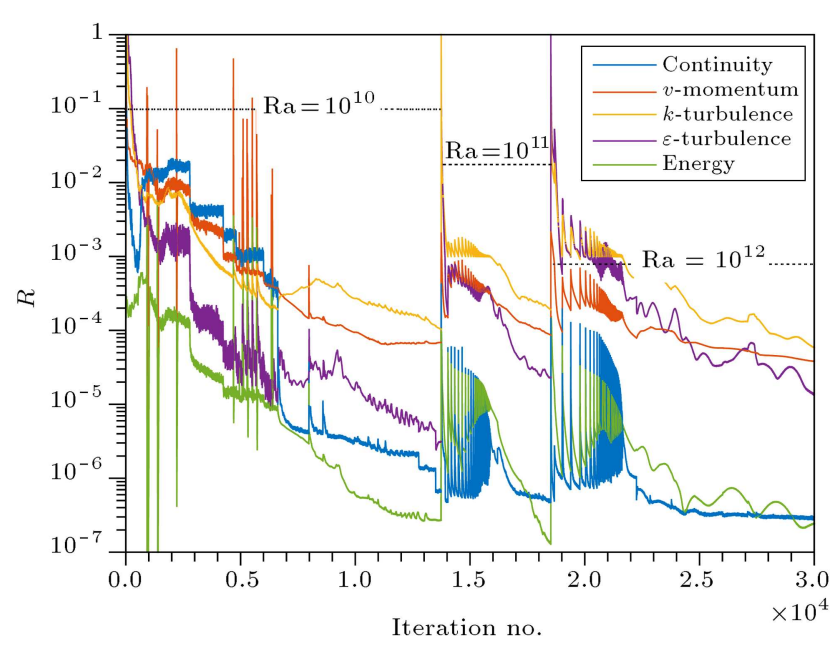

Figure 2. Evolution of residuals versus iteration numbers for all discretized equations.

mode by having access to a more physical initial guess obtained from previous steady-state solution, leading to a significant decrease in the computational cost. The unsteady calculation based on fully implicit scheme is adopted with time steps equal to $\Delta t \sqrt{g \beta \Delta T H} / H=$ 0.25 . Iterations in each time step are preceded until the residuals meet the defined convergence criteria; then, the obtained fields are employed as the initial guess for the next time step. Following a careful examination of the iterations, it is found that using under-relaxationfactors equal to 0.2 for momentum and 0.8 for energy equations accelerates the rate of convergence in each time step for the transient mode. When the solution converges at $\mathrm{Ra}=10^{10}$, the results are supplied for the calculation of $\mathrm{Ra}=10^{11}$ as the initial guess, and this procedure is repeated for $\mathrm{Ra}=10^{12}$. The evolution of the residuals versus iterations number is indicated in Figure 2.

Although convergence criteria have been based on residuals, the best criterion to determine the converged solution regarding enclosed natural convection is to monitor an integrated quantity such as averaged Nusselt number of bodies. Based on this definition, iterations for each Rayleigh number continue until the unsteadiness dies out, and the solution reaches a steady state. In these circumstances, the averaged Nusselt numbers of the enclosure walls and bodies remain constant, and more iteration makes no further changes in the final solution.

\subsection{Validation of the numerical scheme}

In order to validate the present numerical results, the distribution of temperature and velocity in a square enclosure with the isothermal side walls and the adiabatic horizontal walls at $\mathrm{Ra}=1.58 \times 10^{9}$ are reported in the following figures. Figure 3(a)-(c) illustrate temperature distribution near the hot and cold walls at level $Y=0.5$ as well as the vertical velocity. The 


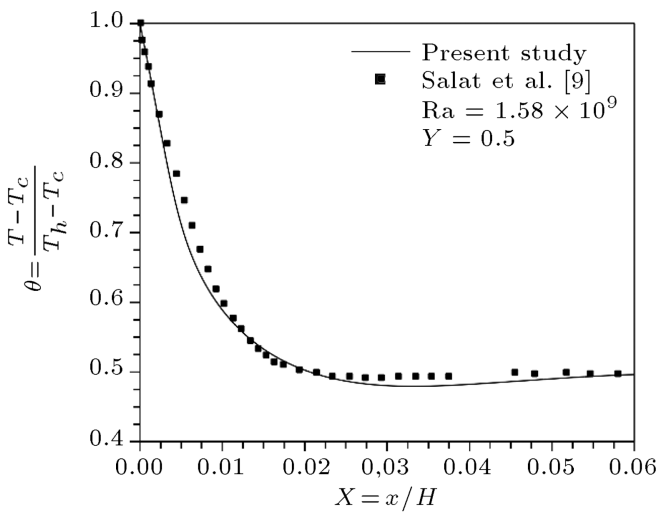

(a)

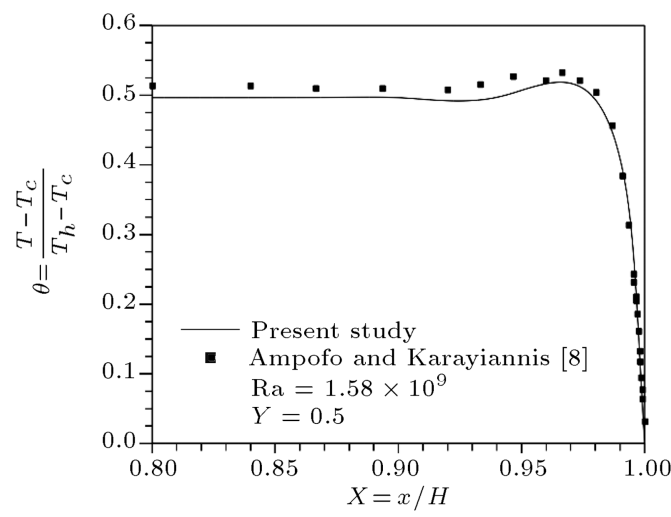

(b)

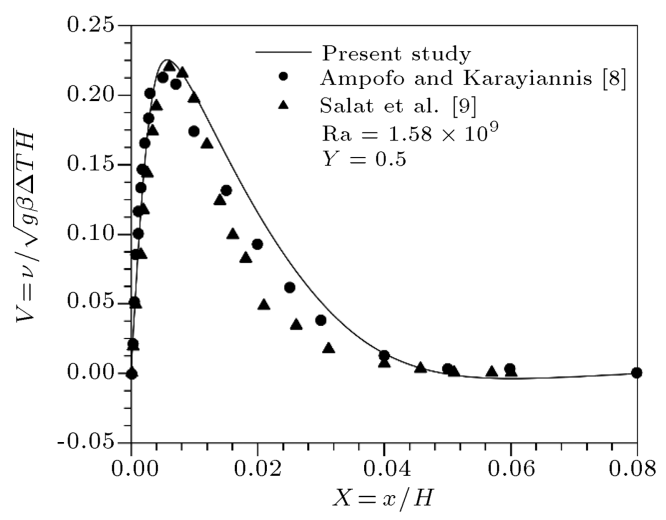

(c)

Figure 3. (a) Temperature near the hot wall, (b) temperature near the cold wall, and (c) vertical velocity, all at $Y=0.5$.

experimental data of Ampofo and Karayiannis [8] and Salat et al. [9] are also included in the figures for comparison. Although the dimensions and temperature of two enclosures are different in these two experiments, the Rayleigh and Prandtl numbers in both cases are almost equal. Consequently, these two experiments are treated identically in our investigation, since all of the non-dimensional governing equations, boundary conditions, and Rayleigh and Prandtl numbers are the same. These figures confirm the agreement between the present and previous experimental results.

Figure 4(a)-(c) show another case of validation in which the vertical velocity at the level of $Y=0.7$ and 0.85 , temperature distribution at $X=0.5$, and the local Nusselt number along the hot wall related to the two tall enclosures with isothermal vertical and adiabatic horizontal walls are plotted at two different Rayleigh numbers of $\mathrm{Ra}=5 \times 10^{10}$ and $\mathrm{Ra}=1.2 \times 10^{11}$. The experimented data of Bowles and Cheesewright [1] and Saury et al. [2] are also included for comparison.

Figure 5 depicts the numerical results of the present work at higher Rayleigh numbers in the range of $10^{8} \leq \mathrm{Ra} \leq 10^{16}$ with the data of Henkes et al. [17] for comparison. In the figure, the Nusselt number of the hot wall obtained by standard $k-\varepsilon$ turbulence model and those reported by Henkes et al. [17] via standard and Chien low Reynolds number $k-\varepsilon$ models are included. There is close agreement between the results; however, the Chien low Reynolds number $k-\varepsilon$ model predicts lower values of the Nusselt number through the wall of the enclosure.

Figure 6(a)-(c) present the isotherm lines, streamlines, and averaged Nusselt number of the hot body at $\mathrm{Ra}=10^{7}$. To show the credibility of the heat transfer through the isothermal walls of the bodies, a laminar natural convection for water $(\mathrm{Pr}=5.66)$ as working fluid is modeled in an adiabatic square enclosure with two heated and two cooled bodies. The data of Garoosi et al. [39] regarding the averaged Nusselt numbers are also presented for comparison.

\subsection{Grid independency}

Grid independent study shows us that the calculation results are almost fixed along with a denser or looser grid such that the truncation error in numerical simulation can be ignored. In order to find the proper size of the grid, especially near the walls, grid independency is required to be checked. This evaluation has been carried out for a square enclosure including a single square hot body, as shown in Figure 1(a), to determine 


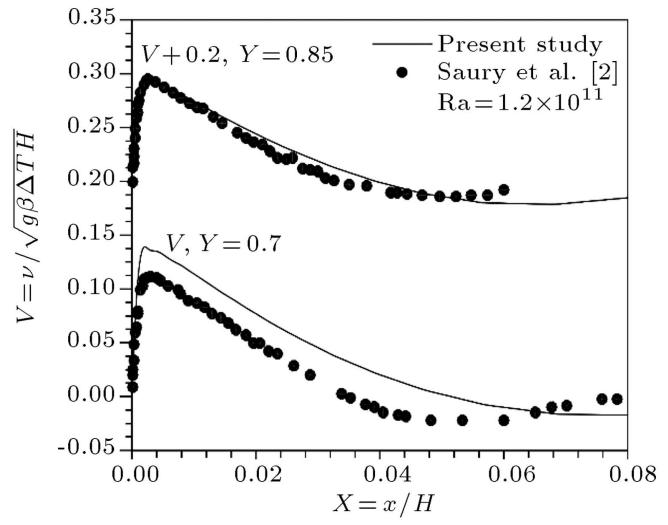

(a)

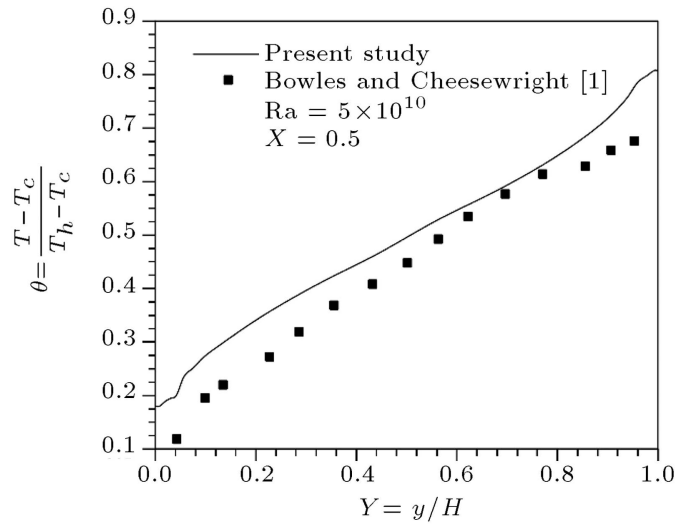

(b)

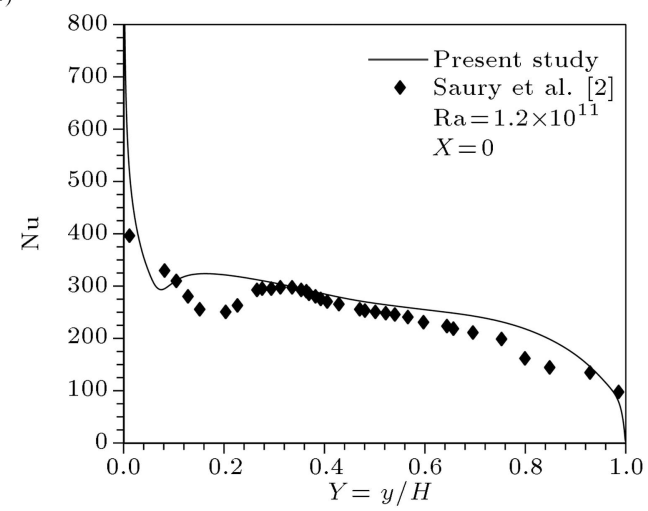

(c)

Figure 4. (a) Vertical velocity at $Y=0.7$ and 0.85 near the hot wall. (b) Temperature distribution at $X=0.5$. (c) Local Nusselt number along the hot wall.

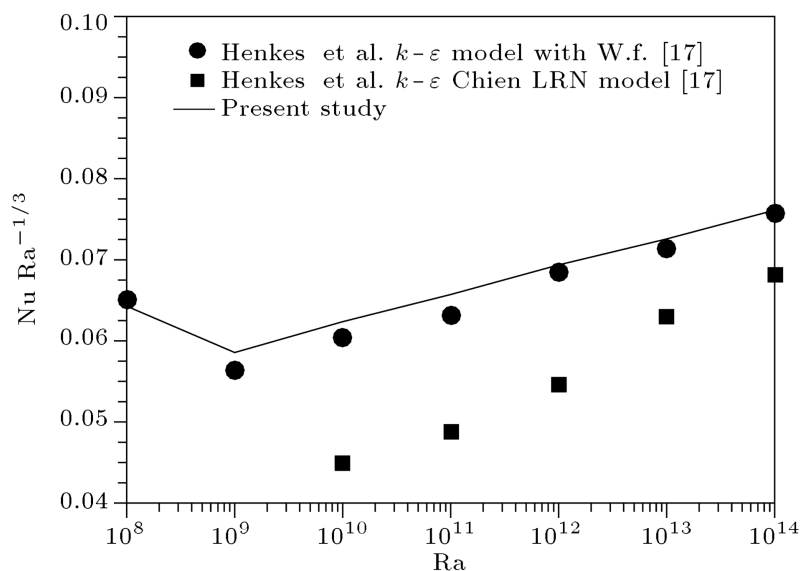

Figure 5. Averaged Nusselt number for hot wall in the square enclosure.

the best grid size with which the most accurate results with a reasonable cost of computation are attainable.

Such a grid should be adequately concentrated near the walls of the enclosure and bodies; however, it can be coarse and away from the surfaces. Five initial values have been chosen for the size of the first cell adjacent to the wall, and the concentration factor has been kept constant, leading to the generation of the grids whose sizes are reported in Table 2. Figure 7 indicates the grid independence results of the averaged Nusselt number of the left wall and local Nusselt number at its middle regarding the enclosure, including a single heated body at three Rayleigh numbers of $10^{10}, 10^{11}$, and $10^{12}$ it is observed that both Nusselt numbers approach their corresponding constant values when the number of grid cells is about $144^{2}$ for all the aforementioned Rayleigh numbers.

\section{Results and discussion}

The numerical method is used to simulate the turbulent natural convection inside an enclosure including four square or rectangular bodies. The preliminary investi-

Table 2. Size of the first cell adjacent to the walls and number of grid cells.

\begin{tabular}{lccccc}
\hline & \multicolumn{5}{c}{ No. of grid } \\
\cline { 2 - 6 } & $\mathbf{9 6}^{\mathbf{2}}$ & $\mathbf{1 1 2}^{\mathbf{2}}$ & $\mathbf{1 3 0}^{\mathbf{2}}$ & $\mathbf{1 4 4}^{\mathbf{2}}$ & $\mathbf{1 6 2}^{\mathbf{2}}$ \\
\hline First cell size & $2.5 \times 10^{-4}$ & $1.25 \times 10^{-4}$ & $5 \times 10^{-5}$ & $2.5 \times 10^{-5}$ & $10^{-5}$ \\
\hline
\end{tabular}




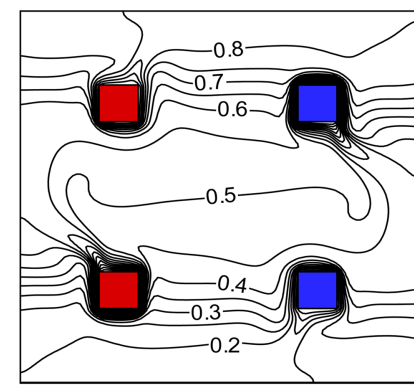

(a)

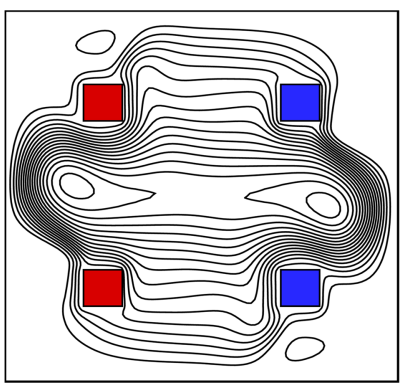

(b)

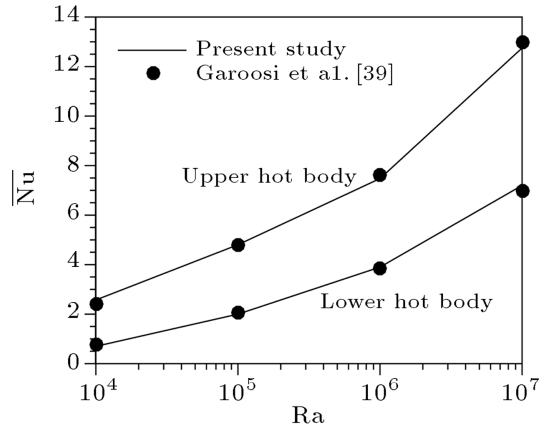

(c)

Figure 6. Enclosure filled with water $(\operatorname{Pr}=5.66)$ : (a) Isotherm lines, (b) streamlines at $\mathrm{Ra}=10^{7}$, and $(\mathrm{c})$ averaged Nusselt number of hot body.

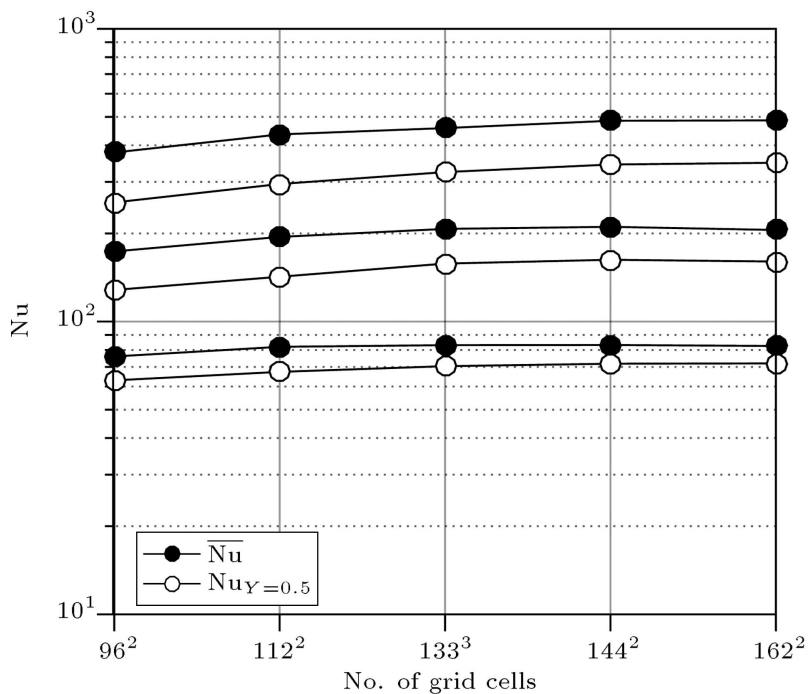

Figure 7. Averaged and local Nusselt numbers of the enclosure's left wall and at $Y=0.5$.

gations are devoted to the enclosure with one interior hot body at $\mathrm{Ra}=10^{12}$, and further investigations are focused on the enclosure with two hot and two cold bodies in the range of Rayleigh numbers of $10^{10} \leq \mathrm{Ra} \leq$ $10^{12}$.

\subsection{Enclosure with one interior body}

Figure 8(a) and (b) report streamlines and isotherms inside an enclosure with a single square interior hot body. In Figure 8(a), natural convection is initiated in the proximity of the hot body above which a plume ascends toward the upper insulated wall by establishing two vortices in the upper part of the enclosure, the right-hand side of which is clockwise and the other one is counter-clockwise. Subsequently, downward fluid flow forms near the wall of the enclosure. The temperature field takes shape such that thermal stratification is established in the core region with a zero gradient in horizontal direction except near the walls. At lower parts of the enclosure, no flow is induced by natural convection, and the isothermal values are zero and

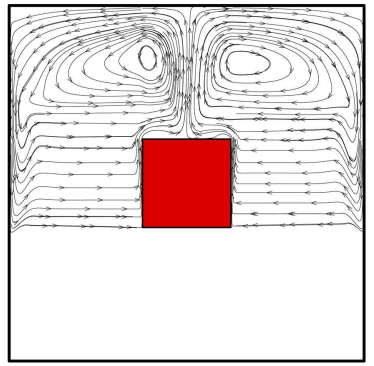

(a)

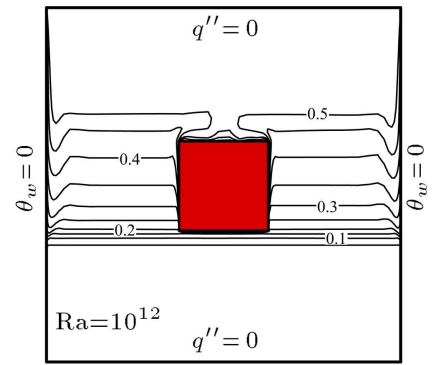

(b)
Figure 8. Air-filled square enclosure: (a) Streamlines, and (b) isotherms at $\mathrm{Ra}=10^{12}$.

equal to the temperature of the side walls. The results indicate that the averaged Nusselt number of the body is $\overline{\mathrm{Nu}}_{b}=699$ and the corresponding value of each vertical wall is $\overline{\mathrm{Nu}}_{w}=338$, showing that the heat transfer of the body is almost equal to that of both side walls combined.

\subsection{Enclosure with four interior bodies}

Figure 9(a)-(d) illustrate streamlines in four enclosures with different interior bodies, yet with the same surface area equal to 1 . In all of the enclosures except that in Figure 9(b), the center of bodies is located at the intersection of the upper and lower midwidth lines with the left and right midheight lines of the enclosure so that, in Figure 9(a), the distance between the edges of bodies equals 0.25 bisected in the second state of Figure 9(b) to investigate its effect on the heat transfer rate inside the enclosure. In Figure 9(c) and (d), the effect of aspect ratio is due to be investigated, and they are installed with $h / w=1 / 3$ and 3 , respectively, in these two states. A pair of vortices is formed on the top and bottom of the hot and cold bodies, respectively. The initial increase and decrease of air temperature at the vicinity of the bodies begin by conductance mechanism of heat transfer. Then, due to the appearance of a temperature difference inside the domain, the heat transfer mechanism is changed to natural convection that induces downward and upward 


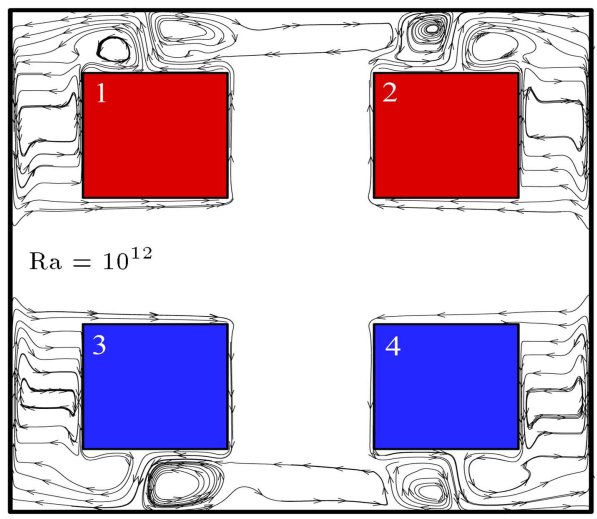

(a)

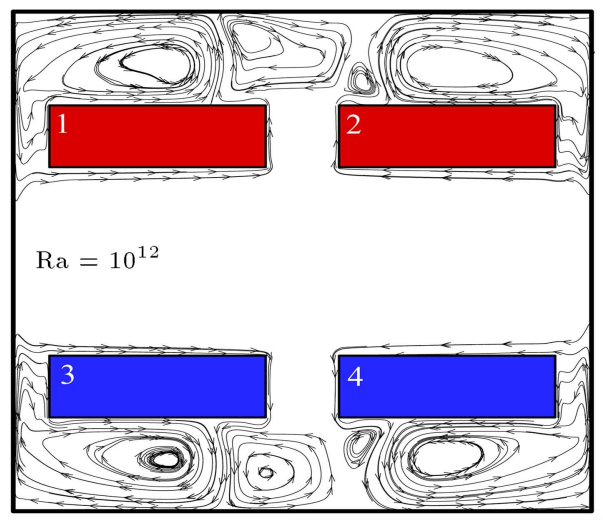

(c)

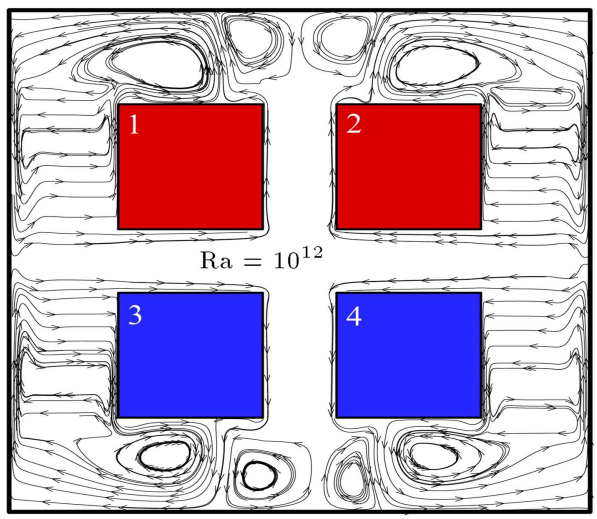

(b)

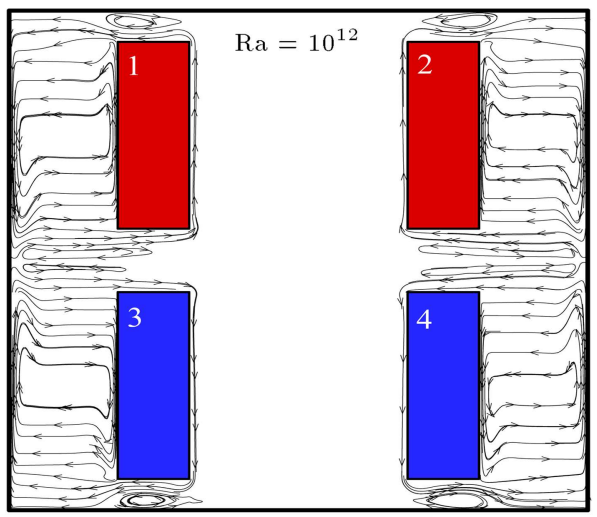

(d)

Figure 9. Streamlines in a square enclosure at $\mathrm{Ra}=10^{12}$ : horizontal walls are adiabatic, both vertical walls are at $\theta_{w}=0.5$, hot bodies are at $\theta_{h}=1$, and cold bodies are at $\theta_{c}=0$.

flows adjacent to the cold and hot bodies, leading to the formation of descending and ascending plumes below and above them, respectively. These plumes reach the top and bottom of the insulated walls and circulate there toward the side walls of the enclosure. Since the temperature of flows at the upper part of the enclosure is greater than that of the vertical walls, downward flows take shape in the proximity of these walls. At the lower part of the enclosure, four similar vortices beneath the cold bodies are formed. It is also obvious that the size of vortices is proportional to the distance between the bodies and the walls of the enclosure. Therefore, when the bodies are placed closer to each other as shown in Figure 9(b) or installed horizontally in Figure 9(c), the distance between the bodies and the walls increases; as a result, two larger vortices are formed compared to Figure 9(a). Similarly, the size of these vortices is reduced when the interior bodies are positioned vertically in Figure 9(d). In the latter state, there are only four vortices within the enclosure, and the other vortices closer to the side walls disappear due to the very narrow distance existing between the bodies and insulated walls.

Figure 10(a) and (b) represent the vertical ve- locity at the midheight above and below the left hot and cold bodies respectively in order to have a more in-depth view over the induced flow and to see how the distance between the bodies affects on the velocity field. The magnitude of the maximum velocity at the midheight above and below the bodies is also proportional to the distance between the bodies and insulated walls of the enclosure. These velocities will be enhanced by about 45 percent when the bodies get closer to each other from $d=0.25$ to $d=$ 0.125. Furthermore, the locations of the peaks in the $X$-direction exactly coincide with the position of ascending and descending plumes over and below the hot and cold bodies, respectively. In a similar manner, to see how the aspect ratio affects on the velocity field, the vertical air velocity above the hot and below the cold bodies are plotted in Figure 10(a), (c), (b), and (d) respectively. The lines in Figure 10(a) and (b) belong to the horizontal distance between two bodies, i.e., $d=0.125$ and 0.25 . Whereas, the lines in Figure 10(c) and (d) belong to the aspect ratio of $h / w=1 / 3,1$, and 3. Installation of vertical position with $h / w=3$ has a great impact on maximum velocities compared to the configuration with square bodies and $h / w=1$. 


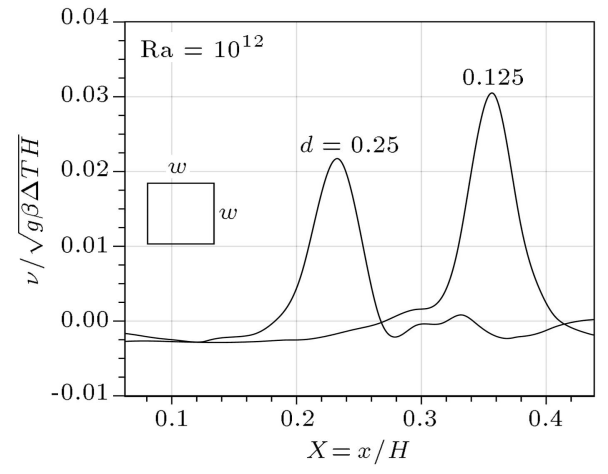

(a)

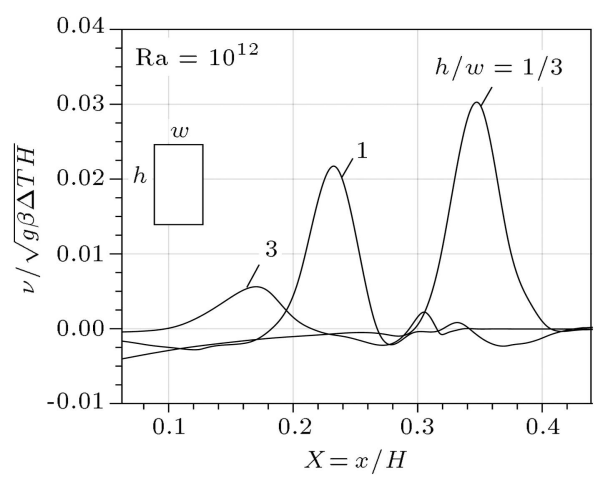

(c)

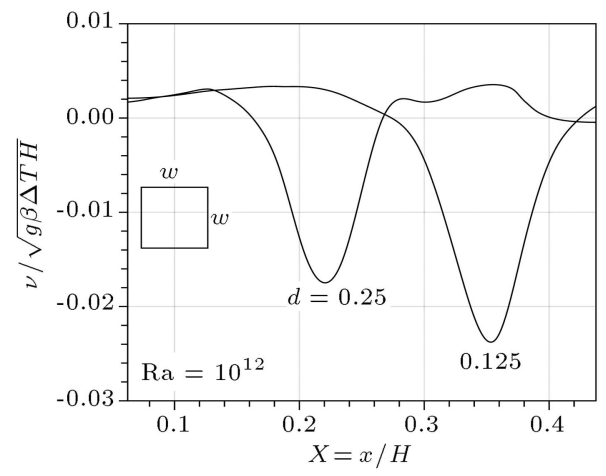

(b)

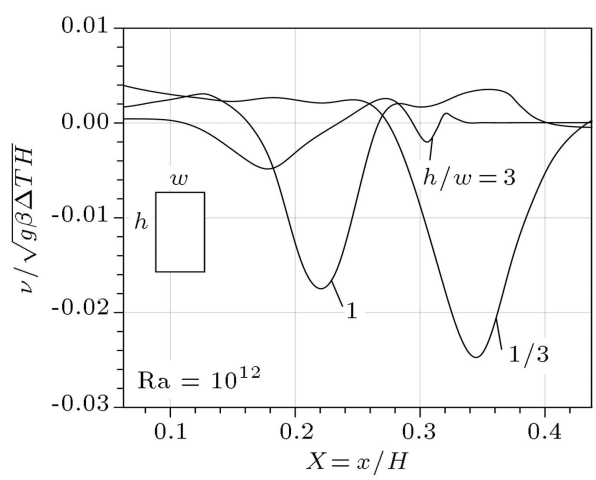

(d)

Figure 10. Vertical velocity at the midheight above the left hot bodies ((a) and (c)) and under the left cold bodies ((b) and (d)). (a) and (b) belong to the case that the distance between two bodies are $d=0.125$ and 0.25 , (c) and (d) are related to the case that the aspect ratios are $h / w=1 / 3,1$, and 3 .

Figure 11(a)-(d) report the detailed information of temperature field within the enclosures of Figure 9 (a)-(d). The temperature field is completely stratified in the entire domain, and the temperature gradient along the horizontal direction is almost zero except for the regions in the vicinity of walls. The boundary layer adjacent to the side walls and near the adiabatic horizontal walls is extremely thin and thickens by moving toward the downstream of the flow. Such behavior of the boundary layer results in the variation of the local Nusselt number of vertical walls to be the same as Figure 12(a) and (b). In fact, the high rate of heat transfer occurs at locations where the boundary layer is thin and decreases when the boundary layer is thick. Accordingly, the local Nusselt number becomes exceedingly close to zero in the middle of the side walls corresponding to the maximum thickness of the boundary layer and increases afterward. It is worth noting that, at the upper half of the enclosure, the fluid temperature is greater than the vertical walls temperature, and the heat transfer direction is from the air to the walls of the enclosure. Conversely, at the lower half of the enclosure, the direction of heat transfer is from the walls to the air.

Table 3 provides the information of the averaged Nusselt numbers of bodies in the range of $10^{10} \leq$
Ra $\leq 10^{12}$. In the table, "a" and "b" belong to the bodies of square shape, and "c" and "d" belong to the rectangular shape. When the gap between the bodies is reduced from $d=0.25$ to $d=0.125$, the averaged Nusselt number is promoted to $3.8,7.3$, and 11.9 percent for $10^{10}, 10^{11}$, and $10^{12}$, respectively. When the aspect ratio is changed from $h / w=1$ to $1 / 3$, the rate of the Nusselt number is changed to $12.9,8.3$, and 3.8 percent corresponding to the Rayleigh numbers of $10^{10}, 10^{11}$, and $10^{12}$, respectively. When the aspect ratio is $h / w=3$, this configuration brings about 3.1, 3.5 , and 4.8 percent of Nusselt number augmentation corresponding to Rayleigh numbers of $10^{10}, 10^{11}$, and $10^{12}$, respectively. Moreover, the averaged Nusselt number of all configurations is promoted nearly by 100 percent for increasing the Rayleigh number from $10^{10}$, to $10^{11}$, and $10^{12}$, subsequently.

\section{Concluding remarks}

This study focused on the numerical solution of turbulent natural convection inside a square air-filled enclosure including one or four hot and cold bodies via the standard $k-\varepsilon$ turbulence model based on the standard wall functions approach at high Rayleigh numbers. The shape of the internal bodies is square or 


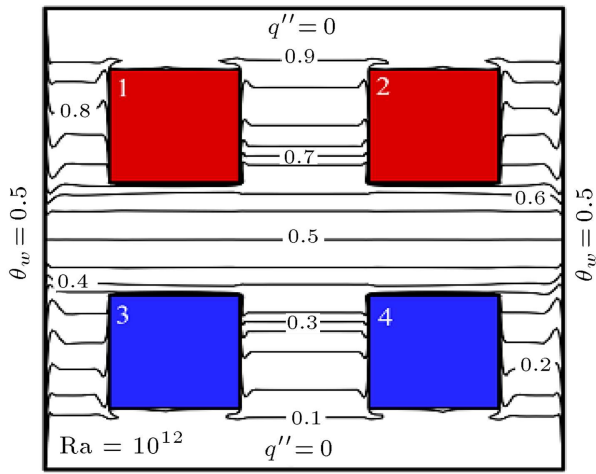

(a)

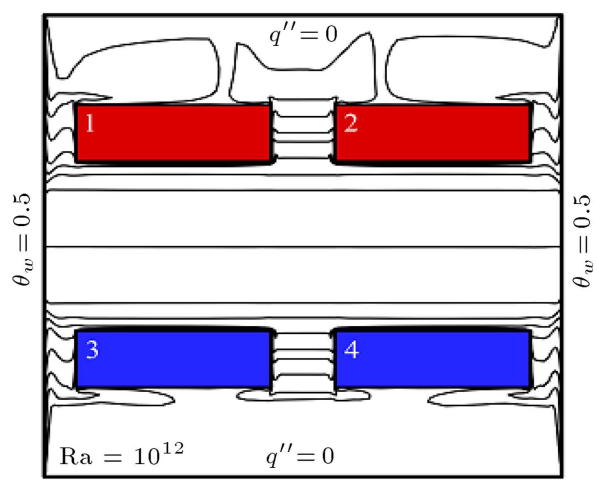

(c)

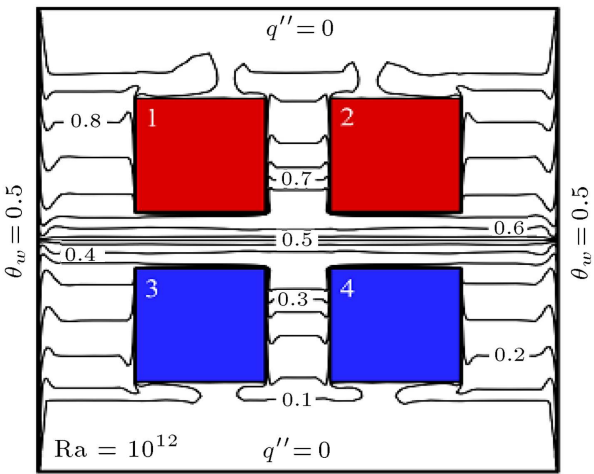

(b)

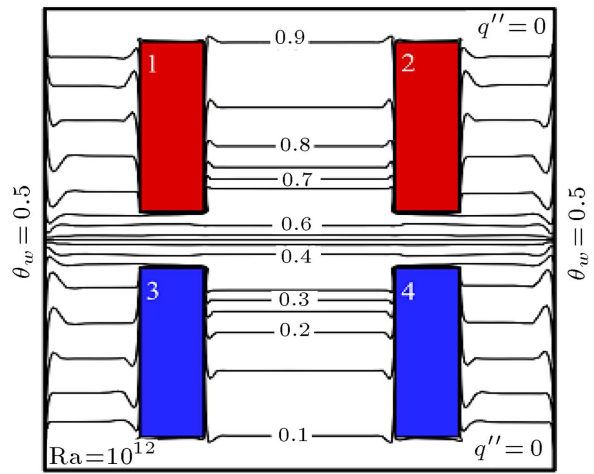

(d)

Figure 11. Isotherms in a square enclosure at $\mathrm{Ra}=10^{12}$ : horizontal walls are adiabatic, both vertical walls are at $\theta_{w}=0.5$, hot bodies are at $\theta_{h}=1$, cold bodies are at $\theta_{c}=0$.

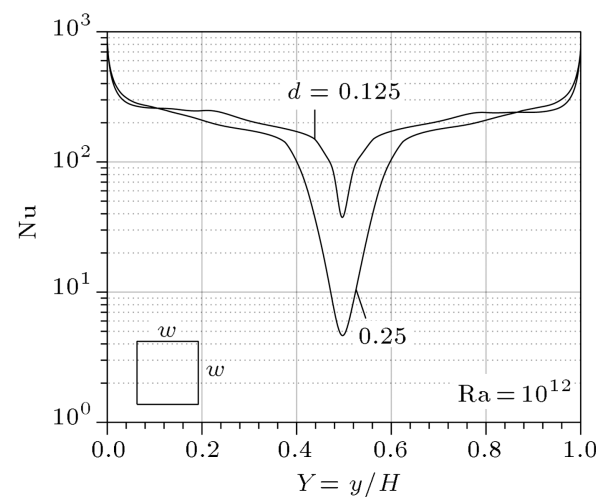

(a)

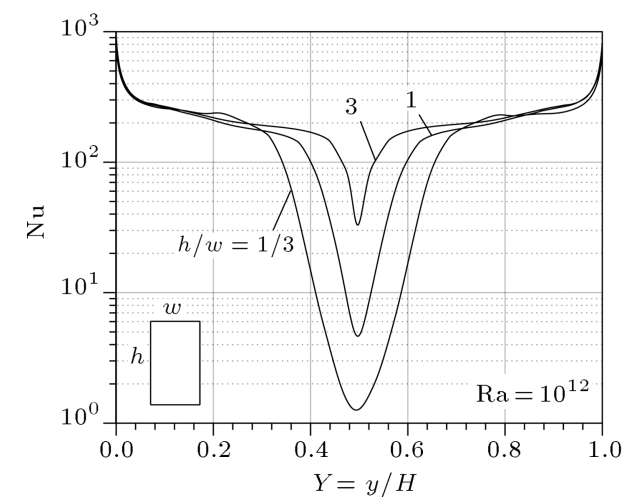

(b)

Figure 12. Local Nusslet number along the left wall of the enclosure including two hot and two cold bodies: (a) Two different horizontal distances between two bodies of $d=0.125$ and 0.25 and (b) three different aspect ratios of $h / w=1 / 3$, 1 , and 3 .

rectangular with different aspect ratios, yet with the same surface areas. The horizontal and vertical walls of the enclosure are considered adiabatic and isothermal, respectively. The main purpose of the present work is to investigate the effects of distance between the bodies, their aspect ratios, and governing the Rayleigh number on heat transfer rate. The findings of this work indicate that the critical Rayleigh number in which the transition from laminar to turbulent flow takes place is about $10^{9}$. In all of the considered configurations, the temperature field is partly or entirely stratified, especially in the region over the cold and under the hot bodies for the enclosure containing two pairs of heated and cooled bodies. This stratification is intensified with the reduction of the mentioned distance when the bodies are mounted in a halved distance from each other or oriented vertically with $h / w=3$. Moreover, the highest reduction of the Nusselt number at high Rayleigh numbers is achieved by doubling the distance between square bodies through which 
Table 3. Averaged Nusselt numbers of bodies in the enclosure for four cases of a-d.

\begin{tabular}{|c|c|c|c|c|c|}
\hline \multirow[t]{2}{*}{$R a$} & \multirow[t]{2}{*}{ Position of body } & \multicolumn{4}{|c|}{$\overline{\mathbf{N u}}_{b}$} \\
\hline & & $\mathbf{a}$ & b & c & d \\
\hline \multirow{6}{*}{$10^{10}$} & 1 & 30.92 & 30.21 & 25.25 & 30.85 \\
\hline & 2 & 31.06 & 30.12 & 25.56 & 30.68 \\
\hline & 3 & 28.98 & 31.81 & 26.69 & 31.26 \\
\hline & 4 & 29.11 & 32.57 & 27.06 & 31.06 \\
\hline & $0.25 \sum\left(\mathrm{Nu}_{b}\right)_{i}$ & 30.01 & 31.17 & 26.14 & 30.96 \\
\hline & Compared with (a) & 1 & $3.8 \%$ & $-12.9 \%$ & $3.1 \%$ \\
\hline \multirow{6}{*}{$10^{11}$} & 1 & 58.06 & 58.57 & 50.35 & 59.01 \\
\hline & 2 & 58.34 & 61.89 & 52.17 & 58.47 \\
\hline & 3 & 56.32 & 61.76 & 52.07 & 60.19 \\
\hline & 4 & 56.46 & 63.74 & 55.42 & 59.52 \\
\hline & $0.25 \sum\left(\mathrm{Nu}_{b}\right)_{i}$ & 57.29 & 61.49 & 52.5 & 59.30 \\
\hline & Compared with (a) & 1 & $7.3 \%$ & $-8.3 \%$ & $3.5 \%$ \\
\hline \multirow{6}{*}{$10^{12}$} & 1 & 113.85 & 124.36 & 107.57 & 118.24 \\
\hline & 2 & 113.80 & 125.42 & 105.40 & 116.94 \\
\hline & 3 & 112.79 & 128.58 & 112.19 & 120.76 \\
\hline & 4 & 112.60 & 128.49 & 110.61 & 118.57 \\
\hline & $0.25 \sum\left(\mathrm{Nu}_{b}\right)_{i}$ & 113.26 & 126.71 & 108.94 & 118.63 \\
\hline & Compared with (a) & 1 & $11.9 \%$ & $-3.8 \%$ & $4.8 \%$ \\
\hline
\end{tabular}

the Nusselt number decreases by $3.8,7.3$, and 11.9 percent corresponding to $\mathrm{Ra}=10^{10}, 10^{11}$, and $10^{12}$, respectively. The maximum reduction of the Nusselt number at low values of the Rayleigh number pertains to the horizontal installation of bodies with $h / w=1 / 3$, resulting in $12.9,8.3$, and 3.8 percent of a reduction in the Nusselt number at the Rayleigh numbers of $10^{10}$, $10^{11}$, and $10^{12}$, respectively. The vertical positioning of bodies with $h / w=3$ is accompanied by $3.1,3.5$, and 4.8 percent of promotion in the Nusselt number at the mentioned Rayleigh numbers. Moreover, by increasing the Rayleigh number from $10^{10}$, to $10^{11}$, and $10^{12}$, the Nusselt number is approximately augmented by 100 percent for all configurations.

\section{Nomenclature}

c Constant coefficients

d Dimensionless distance between bodies

$g \quad$ Gravitational acceleration, $\mathrm{ms}^{-2}$

$G_{k} \quad$ Production of turbulent kinetic energy

$h \quad$ Body height, $\mathrm{m}$

$H \quad$ Enclosure height, $\mathrm{m}$

$k \quad$ Turbulent kinetic energy, $\mathrm{m}^{2} / \mathrm{s}^{2}$
$K \quad$ Dimensionless turbulent kinetic energy

$N \quad$ Dimensionless numbers

$\mathrm{Nu} \quad$ Local Nusselt number

$p \quad$ Pressure, $\mathrm{Pa}$

$P \quad$ Dimensionless pressure

$P_{k} \quad$ Shear production of turbulent kinetic energy

$\operatorname{Pr} \quad$ Prandtl number, $\nu / \alpha$

$q^{\prime \prime} \quad$ Heat flux, $\mathrm{W} / \mathrm{m}^{2}$

$R \quad$ Residual

Ra Rayleigh number, $g \beta\left(T_{h}-T_{c}\right) H^{3} / \alpha \nu$

$S \quad$ Source term

$t \quad$ Dimensionless time

$T \quad$ Temperature, $\mathrm{K}$

$\Delta T \quad$ Temperature difference, $T_{h}-T_{c}$

$u, v \quad$ Dimensional velocity components, $\mathrm{m} / \mathrm{s}$

$U, V \quad$ Dimensionless velocity components

$u_{\tau} \quad$ Shear velocity, $\sqrt{\nu \partial U_{t} / \partial y_{n}}$

$w \quad$ Body width, $\mathrm{m}$

$x, y \quad$ Cartesian coordinates, $\mathrm{m}$

$X, Y$ Dimensionless Cartesian coordinates, $x / H, y / H$ 


\section{Greek symbols}

$\beta \quad$ Thermal expansion coefficient, $1 / \mathrm{K}$

$\varepsilon \quad$ Dimensionless kinetic energy dissipation rate

$\phi \quad$ General variable

$\lambda$ Parameter

$\Gamma \quad$ Transport property

$\nu \quad$ Dimensionless kinematic viscosity

$\theta \quad$ Temperature, $\left(T-T_{c}\right) /\left(T_{h}-T_{c}\right)$

$\rho \quad$ Dimensionless density

$\sigma \quad$ Turbulent Prandtl number

\section{Subscripts}

$b \quad$ Interior body

c Cold, center of body

$h \quad$ Hot

$n \quad$ Closest grid to wall

ref Reference

$t \quad$ Turbulent

$w \quad$ Enclosure wall

$\varepsilon \quad$ Dissipation energy rate

$k \quad$ Turbulent kinetic energy

\section{Superscripts}

$\begin{array}{ll}- & \text { Average } \\ * & \text { Dimensional variable }\end{array}$

\section{Acknowledgement}

The authors would like to express their gratitude and thanks to the Research Deputy of Sharif University of Technology for the financial support of this research under the contract no. QB970915.

\section{References}

1. Bowles, A. and Cheesewright, R. "Direct measurements of the turbulence heat flux in a large rectangular air cavity", Experimental Heat Transfer, 2, pp. 59-69 (1989). DOI: 10.1080/08916158908946354

2. Saury, D., Rouger, N, Djanna, F., and Penot, F. "Natural convection in an air-filled cavity: Experimental results at large Rayleigh numbers", Int. Communications of Heat and Mass Transfer, 38, pp. 679-687 (2011). DOI: $10.1016 /$ j.icheatmasstransfer.2011.03.019

3. Dafa'Alla, A.A. and Betts, P.L. "Experimental study of turbulent natural convection in a tall air cavity", Exp. Heat Transfer, 9, pp. 165-194 (1996). DOI: 10.1080/08916159608946520

4. Betts, P.L. and Bokhari, I.H. "Experiments on turbulent natural convection in an enclosed tall cavity", Int. J. of Heat and Fluid Flow, 21, pp. 675-683 (2000). DOI: $10.1016 / \mathrm{S} 0142-727 \mathrm{X}(00) 00033-3$
5. Kirkpatrick, A.T. and. Bohn, M. "An experimental investigation of mixed cavity natural convection in the high Rayleigh number regime", Int. J. of Heat and Mass Transfer, 29, pp. 69-82 (1986). DOI: 10.1016/0017-9310(86)90035-9

6. Tian, Y.S. and Karayiannis, T.G. "Low turbulence natural convection in an air filled square cavity", Part I, Int. J. of Heat and Mass Transfer, 43, pp. 849-866 (2000). DOI: 10.1016/S0017-9310(99)00199-4

7. Tian, Y.S. and Karayiannis, T.G. "Low turbulence natural convection in an air filled square cavity", Part II, Int. J. of Heat and Mass Transfer, 43, pp. 867-884 (2000). DOI: 10.1016/S0017-9310(99)00200-8

8. Ampofo, F. and Karayiannis, T.G. "Experimental benchmark data for turbulent natural convection in an air filled square cavity", Int. J. of Heat and Mass Transfer, 46, pp. 3551-3572 (2003). DOI: 10.1016/S0017-9310(03)00147-9

9. Salat, J., Xin, S., Joubert, P., Sergent, A., Penot, F., and Le Quéré, P. "Experimental and numerical investigation of turbulent natural convection in a large air-filled cavity", Int. J. of Heat and Fluid Flow, 25, pp. 824-832 (2004). DOI: 10.1016/j.ijheatfluidflow.2004.04.003

10. De Vahl Davis, G. "Natural convection of air in a square cavity: a bench mark numerical solution", Int. J. for Numerical Methods in Fluids, 3, pp. 249-264 (1983). DOI: 10.1002/fld.1650030305

11. Hortmann, M. Peric, M., and Scheuerer, G. "Finite volume multigrid prediction of laminar natural convection: Bench-mark solutions", Int. J. for Numererical Methods in Fluids., 11, pp. 189-207(1990). DOI: 10.1002/fld.1650110206

12. Le Quere, P. "Accurate solutions to the square thermally driven cavity at high Rayleigh number", Computers \& Fluids, 20(1), pp. 29-41 (1991). DOI: 10.1016/0045-7930(91)90025-D

13. Phillips, T.N. "Natural convection in an enclosed cavity", J. of Computational Physics, 54(3), pp. 365381 (1984). DOI: 10.1016/0021-9991(84)90123-2

14. Launder, B.E. and Spalding, D.B. "The numerical computation of turbulent flows", Computer Methods in Applied Mechanics and Engineering, 3, pp. 269-289 (1974). DOI: 10.1016/0045-7825(74)90029-2

15. Ince, N.Z. and Launder, B.E. "On the computation of buoyancy-driven turbulent flows in rectangular enclosures", Int. J. of Heat and Fluid Flow, 10, pp. 110-117 (1989). DOI: $10.1016 / 0142-727 X(89) 90003-9$

16. Jones, W.P. and Launder, B.E. "The prediction of laminarization with a two-equation model of turbulence", Int. J. of Heat and Mass Transfer, 15, pp. 301-314 (1972). DOI: 10.1016/0017-9310(72)90076-2 
17. Henkes, R.A.W.M., Van Der Vlugt, F.F., and Hoogendoorn, C.J. "Natural-convection flow in a square cavity calculated with low-Reynolds-number turbulence models", Int. J. of Heat and Mass Transfer, $\mathbf{3 4}$ pp. 377-388 (1991). DOI: $10.1016 / 0017-9310(91) 90258-G$

18. Barakos, G. and Mitsoulis, E. "Natural convection flow in a square cavity revisited: laminar and turbulent models with wall functions", Int. J. for Numerical Methods in Fluids, 18, pp. 695-719 (1994). DOI: 10.1002/fld.1650180705

19. Chen, Q. "Comparison of different $k-\varepsilon$ models for indoor air flow computations", Numer. Heat Transf. Part B Fundamental, 28, pp. 353-369 (1995). DOI: 10.1080/10407799508928838

20. Trias, F.X., Gorobets, A., Soria, M., and Oliva, A. "Direct numerical simulation of a differentially heated cavity of aspect ratio 4 with Rayleigh numbers up to $10^{11}$ - Part I: Numerical methods and time-averaged flow", Int. J. of Heat and Mass Transfer, 53, pp. 665-673 (2010). DOI: 10.1016/j.ijheatmasstransfer.2009.10.026

21. Trias, F.X., Gorobets, A., Soria, M., and Oliva, A. "Direct numerical simulation of a differentially heated cavity of aspect ratio 4 with Rayleigh numbers up to $10^{11}$ - Part II: Heat transfer and flow dynamics", Int. J. of Heat and Mass Transfer, 53, pp. 674-683 (2010). DOI: $10.1016 /$ j.ijheatmasstransfer.2009.10.027

22. Hsieh, K.J. and Lien, F.S. "Numerical modeling of buoyancy-driven turbulent flows in enclosures", Int. J. of Heat and Fluid Flow, 25, pp. 659-670 (2004). DOI: 10.1016/j.ijheatfluidflow.2003.11.023

23. Hanjalić, K. and Vasić, S. "Computation of turbulent natural convection in rectangular enclosures with an algebraic flux model", Int. J. of Heat and Mass Transfer, 36, pp. 3603-3624 (1993). DOI: 10.1016/00179310(93)90178-9

24. Dol, H.S., Hanjalić, K., and Kenjereš, S. "A comparative assessment of the second-moment differential and algebraic models in turbulent natural convection", Int. J. of Heat and Fluid Flow, 18, pp. 4-14 (1997). DOI: 10.1016/S0142-727X(96)00149-X

25. Craft, T.J., Gant, S.E., Gerasimov, A.V., Iacovides, H., and Launder, B.E. "Development and application of wall-function treatments for turbulent forced and mixed convection flows", Fluid Dynamics Research, 38, pp. 127-144 (2006). DOI: 10.1016/j.fluiddyn.2004.11.002

26. Baïri, A., Zarco-pernia, E., and de Marı J.M.G. "A review on natural convection in enclosures for engineering applications, The particular case of the parallelogrammic diode cavity", Applied Thermal Engineering, 63, pp. 304-322 (2014). DOI: 10.1016/j.applthermaleng.2013.10.065

27. Ho, C.J., Chang, W.S., and Wang, C.C. "Natural convection between two horizontal cylinders in an adiabatic circular enclosure", Transactions of ASME J. of Heat Transfer, 115. pp. 158-165 (1993). DOI: $10.1115 / 1.2910642$
28. Ho, C.J., Cheng, Y.T., and Wang, C.C. "Natural convection between two horizontal cylinders inside a circular enclosure subjected to external convection", Int. J. of Heat and Fluid Flow, 15, pp. 299-306 (1994). DOI: $10.1016 / 0142-727 \mathrm{X}(94) 90015-9$

29. Ha, M.Y, Jung, M.J., and Kim, Y.S. "Numerical study on transient heat transfer and fluid flow of natural convection in an enclosure with a heat generating conducting body, Numerical Heat Transfer, Part A, 35, pp. 415-433 (1999).

30. Ha, M.Y., Kim, I.K., Yoon, H.S., Yoon, K.S., Lee, J.R., Balachandar, S., and Chun, H.H. "TwoDimensional and unsteady natural convection in a horizontal enclosure with a square body", Numerical Heat Transfer, Part A: Applications, 41, pp. 183-210 (2002). DOI: 10.1080/104077802317221393

31. Oztop, H., Dagtekin, I., and Bahloul, A. "Comparison of position of a heated thin plate located in a cavity for natural convection", Int. Commun. Heat Mass Transfer, 31, pp. 121-132 (2004). DOI: 10.1016/S07351933(03)00207-0

32. Oztop, H. and Bilgen, E. "Natural convection in differentially heated and partially divided square cavities with internal heat generation", Int. J. of Heat and Fluid Flow, 27, pp. 466-475 (2006). DOI: 10.1016/j.ijheatfluidflow.2005.11.003

33. Kandaswamy, P., Lee, J., Abdul Hakeem, A.K., and Saravanan, S. "Effect of baffle-cavity ratios on buoyancy convection in a cavity with mutually orthogonal heated baffles", Int. J. of Heat and Mass Transf., 51, pp. 1830-1837 (2008). DOI: 10.1016/j.ijheatmasstransfer.2007.06.039

34. Hakeem, A.K.A., Saravanan, S., and Kandaswamy, P. "Buoyancy convection in a square cavity with mutually orthogonal heat generating baffles", Int. J. of Heat and Fluid Flow., 29, pp. 1164-1173 (2008). DOI: 10.1016/j.ijheatfluidflow.2008.01.015

35. Lee, J.M., Ha, M.Y., and Yoon, H.S. "Natural convection in a square enclosure with a circular cylinder at different horizontal and diagonal locations", Int. J. of Heat and Mass Transfer, 53, pp. 5905-5919 (2010). DOI: $10.1016 /$ j.ijheatmasstransfer.2010.07.043

36. Hussain, S.H. and Hussein, A.K. "Numerical investigation of natural convection phenomena in a uniformly heated circular cylinder immersed in square enclosure filled with air at different vertical locations", Int. Communications in Heat and Mass Transfer, 37, pp. 1115-1126 (2010). DOI: 10.1016/j.icheatmasstransfer.2010.05.016

37. Bararnia, H., Soleimani, S., and Ganji, D.D. "Lattice Boltzmann simulation of natural convection around a horizontal elliptic cylinder inside a square enclosure", Int. Communications of Heat and Mass Transfer, 38, pp. 1436-1442 (2011). DOI: 10.1016/j.icheatmasstransfer.2011.07.012

38. Park, Y.G., Ha, M.Y., Choi, C., and Park, J. "Natural convection in a square enclosure with two inner circular 
cylinders positioned at different vertical locations", Int. J. of Heat and Mass Transfer, 77, pp. 501-518 (2014). DOI: 10.1016/j.ijheatmasstransfer.2014.05.041

39. Garoosi, F., Bagheri, G., and Talebi, F. "Numerical simulation of natural convection of nanofluids in a square cavity with several pairs of heaters and coolers (HACs) inside", Int. J. of Heat and Mass Transfer, 67, pp. 362-376 (2013). DOI: 10.1016/j.ijheatmas stransfer.2013.08.034

40. Garoosi, F. and Hoseininejad, F. "Numerical study of natural and mixed convection heat transfer between differentially heated cylinders in an adiabatic enclosure filled with nanofluid", J. of Molecular Liquids, 215, pp. 1-17 (2016). DOI: 10.1016/j.molliq.2015.12.016

41. Patankar, S. and Spalding, D. "A calculation procedure for heat, mass and momentum transfer in three-dimensional parabolic flows", Int. J. of Heat and Mass Transfer, 15, pp. 1787-1806 (1972). DOI: 10.1016/0017-9310(72)90054-3

42. Stone, H.L. "Iterative solution of implicit approximations of multidimensional partial differential equations", SIAM J. Numerical Analysis, 5(3), pp. 530-558 (1968).

\section{Biographies}

Ali Nouri-Borujerdi is a Professor of Mechanical Engineering at Sharif University of Technology, Tehran, Iran, where he teaches undergraduate and graduate level courses in the Thermal/Fluids Sciences at the School of Mechanical Engineering. His teaching focuses on heat transfer, computational fluid dynamics, and two-phase flows, including boiling and condensation. His current research programs include experimental, theoretical, and numerical works in heat and mass transfer, two-phase flow, and porous media. Professor Nouri has published more than 150 articles in international journals and conferences.

Farzan Sepahi received his BS degree from Shiraz University and MS degree from Sharif University of Technology at the School of Mechanical Engineering in 2013 and 2016, respectively. His research interests include mathematical and numerical modeling, applications of computational fluid dynamics in heat transfer, and turbulence modeling with RANS, LES, and DNS approaches. 